PSICOLOGÍA

IBEROAMERICANA
Psicología Iberoamericana ISSN: 1405-0943

revista.psicologia@ibero.mx

Universidad Iberoamericana, Ciudad de México México

\title{
La lengua y los custodios de la publicación académica
}

Gordon, Sarah Frances

La lengua y los custodios de la publicación académica

Psicología Iberoamericana, vol. 27, núm. 1, 2019

Universidad Iberoamericana, Ciudad de México, México

Disponible en: http://www.redalyc.org/articulo.oa?id=133960951003 


\title{
La lengua y los custodios de la publicación académica
}

\author{
Sarah Frances Gordon sarah.gordon@ibero.mx \\ Universidad Iberoamericana, Ciudad de México, México \\ http://orcid.org/0000-0001-5131-8519
}

Psicología Iberoamericana, vol. 27, núm. 1,2019

Universidad Iberoamericana, Ciudad de México, México

Redalyc: http://www.redalyc.org/ articulo.oa?id=133960951003
El lenguaje juega un papel importante en el mundo de la publicación académica. Los académicos se encuentran bajo una creciente presión para publicar en revistas de alto perfil, y la naturaleza de la publicación académica significa que dichas publicaciones son predominantemente en inglés, lo cual representa un desafío considerable para muchos hablantes no nativos de inglés, ya que se enfrentan a la injusticia y discriminación lingüística. Asimismo, tienen que trabajar considerablemente más duro que los hablantes nativos de inglés para publicar en estas revistas (Hyland, 2016). Los académicos nativos en la lengua inglesa tienen una ventaja comparativa a medida que adquieren el lenguaje de forma natural, mientras que aquellos no nativos de inglés tienen que invertir un tiempo considerable, esfuerzo y dinero en adquirir habilidades del idioma inglés (Hyland, 2016; Salager-Meyer, 2014). Además, los hablantes no nativos de inglés a menudo tienen que contratar a editores que ayuden a corregir sus manuscritos y guiarlos durante un proceso de revisión por pares, el cual puede ser costoso y, tristemente, muchas instituciones académicas de países en desarrollo simplemente no disponen de los recursos necesarios para ello. La redacción de artículos para su publicación en inglés académico es una especialización que toma tiempo en ser perfeccionada y, por lo tanto, aquellos escritores cuyo idioma materno no es el inglés están en una desventaja considerable. Como consecuencia, la sensación de aislamiento que sienten los académicos e investigadores no anglófonos es inevitable, mismos que a menudo viven en países en vías de desarrollo cuyas instituciones cuentan con recursos limitados y escasos presupuestos de investigación, cuando intentan competir en el ámbito académico internacional (Hyland, 2016).

Diversos estudios muestran que los niveles de aceptación en las revistas élite son mayores para aquellas solicitudes provenientes de países anglosajones, particularmente Canadá y Estados Unidos son países favorecidos (Okike, Kocher, Mehlman, Heckman, \& Bhandari, 2008; Saposnik, Ovbiagele, Raptis, Fisher, \& Johnston, 2014). Adicionalmente, académicos cuya segunda lengua es el inglés y presentan artículos para su publicación en revistas anglófonas, frecuentemente reciben comentarios vagos y poco útiles en sus críticas editoriales sobre el uso indebido de la gramática y del inglés académico (Hyland, 2016). Los críticos a menudo 
asumen que los autores deben ser inherentemente conscientes del estilo de inglés académico al que se refieren y no proporcionan suficiente orientación que ayude a los autores a corregir sus errores. Si bien el proceso de dictamen nunca es perfecto, debe haber un mayor esfuerzo por parte de los críticos anglófonos para proporcionar retroalimentación más concreta respecto a cambios lingüísticos que los académicos hispanohablantes deberían hacer, además de la necesidad de un mayor número de revistas académicas multilingües, cuyo lenguaje no sea solamente el inglés.

Los responsables de las revistas académicas deben reconocer el poder del lenguaje en la publicación y su capacidad para reproducir enclaves de desigualdad en la educación superior y la investigación. Asimismo, la publicación académica no debería centrarse en un selecto grupo de angloparlantes, y la elección de publicar en lengua materna nunca debería de ser menospreciada (Hyland, 2016). De hecho, las contribuciones de académicos e investigadores de países emergentes deberían ser altamente valoradas, dado que ofrecen información privilegiada y conocimiento experto sobre los problemas que enfrenta el mundo en vías de desarrollo. Sus contribuciones son muy necesarias en la publicación académica y se le debe dar prioridad a la construcción de una cultura y capacidades de investigación adecuadas en el mundo emergente (Salager-Meyer, 2008).

Psicología Iberoamericana ahora publica artículos tanto en español como en inglés. Nos oponemos a la discriminación lingüística y estamos conscientes de los múltiples desafíos a los cuales se enfrentan los académicos latinoamericanos cuando intentan publicar internacionalmente. Proporcionamos apoyo a los hispanohablantes que desean publicar en inglés con nosotros porque creemos en el desarrollo de nuestros autores.

\section{Referencias}

Hyland, K. (2016). Academic publishing and the myth of linguistic injustice. Journal of Second Language Writing, 31, 58-69. https://doi.org/10.1016 /j.jslw.2016.01.005

Okike, K., Kocher, M. S., Mehlman, C. T., Heckman, J. D., \& Bhandari, M. (2008). Nonscientific factors associated with acceptance for publication in The Journal of Bone and Joint Surgery (American Volume). The Journal of Bone and Joint Surgery (American Volume), 90(11), 2432-2437. https ://doi.org/10.2106/JBJS.G.01687

Salager-Meyer, F. (2008). Scientific publishing in developing countries: Challenges for the future. Journal of English for Academic Purposes, 121132. https://doi.org/10.1016/j.jeap.2008.03.009

Salager-Meyer, F. (2014). Writing and publishing in peripheral scholarly journals: How to enhance the global influence of multilingual scholars? Journal of English for Academic Purposes, 13, 78-82. https://doi.org/10.1 016/j.jeap.2013.11.003

Saposnik, G., Ovbiagele, B., Raptis, S., Fisher, M., \& Johnston, S. C. (2014). Effect of English proficiency and research funding on acceptance of submitted articles to Stroke journal. Stroke, 45(6), 1862-1868. https://d oi.org/10.1161/STROKEAHA.114.005413 


\section{Notas de autor}

sarah.gordon@ibero.mx 